\title{
TAMAN BACA DI BANJARBARU
}

\author{
Husnun Zahidatul Mufidah \\ Program Studi Teknik Arsitektur Fakultas Teknik Universitas Lambung Mangkurat \\ fidazahida09@gmail.com \\ Prima Widia Wastuty \\ Program Studi Teknik Arsitektur Fakultas Teknik Universitas Lambung Mangkurat \\ Primawidiawastuty@ulm.ac.id
}

\begin{abstract}
ABSTRAK
Membaca merupakan salah satu kemampuan dasar yang wajib dikuasai oleh setiap orang. Namun, tingkat baca masyarakat di Indonesia sangatlah rendah. Bahkan, kondisi literasi di Indonesia kini sedang mengalami krisis, yang disebut juga sebagai darurat literasi. Meningkatkan minat baca pada generasi muda di Indonesia saat ini benar-benar penting di tengah begitu banyaknya teknologi yang sangat pesat perkembangannya. Oleh karena itu, Indonesia saat ini tengah gencar melakukan gerakan meningkatkan minat baca. Tujuan dirancangnya Taman Baca ini adalah untuk meningkatkan minat baca masyarakat Indonesia sekaligus menyediakan fasilitas yang cukup untuk membaca bagi masyarakat. Perancangan Taman Baca ini menggunakan metode architectural programming. Proses dari metode ini terbagi menjadi dua tahap yang terdiri dari menyusun program yang merupakan kegiatan menganalisis data yang kemudian menghasilkan permasalahan arsitektural dan merancang desain yang dapat menyelesaikan permasalahan. Digitalisasi buku dapat dijadikan sebagai salah satu cara untuk kembali meningkatkan minat baca anak-anak maupun orang dewasa. Namun, itu saja dirasa masih kurang, karena perlu langkah yang lebih efisien yang dapat lebih mempengaruhi minat membaca dan menarik perhatian masyarakat. Salah satu cara untuk menarik minat masyarakat untuk membaca adalah dengan mengalih fungsikan perpustakaan menjadi suatu tempat baca yang rekreatif. Hal inilah yang mendasari pemikiran mengenai Taman Baca. Menciptakan Taman Baca dengan konsep Ruang Rekreasi diharapkan dapat membantu mengubah pandangan masyarakat tentang membaca yang tadinya membosankan menjadi menyenangkan. Hasil rancangan yaitu ruang membaca yang nyaman, variatif, dan menyenangkan dengan fasilitas yang cukup lengkap.
\end{abstract}

Kata kunci: minat baca, taman baca, ruang rekreasi. 


\begin{abstract}
Reading is one of the basic skills that must be mastered by everyone. However, the reading rate of people in Indonesia is very low. In fact, literacy conditions in Indonesia are now in crisis, which is also called a literacy emergency. Increasing interest in reading in the younger generation in Indonesia today is really important amidst so many technologies that are very rapidly developing. Therefore, Indonesia is currently so active at making movements to increase interest in reading. The purpose of this Community Library is to increase the reading interest of Indonesian people while providing adequate facilities for reading for the community. The design of Community Library uses architectural programming method. The process of this method is divided into two stages consisting of preparing a program that is an activity of analyzing data that led to architectural problems and designing designs that can solve problems. The digitalization of books can be used as a way to increase the children and adults interest in reading again. However, that still feels lacking, because it requires a more efficient steps that can further influence the interest in reading and attract the attention of the public to e interested in reading. One way to attract the reading interest of public to be interested in reading is to turn the library into a creative reading place. This is what underlies the thought of the Community Library. Creating a Community Library with the concept of Recreation Space is expected to help change people's view of reading which was boring to be fun. The design is a comfortable, varied, and fun reading space with complete facilities.
\end{abstract}

Keywords: reading interest, community library, recreational space.

\section{PENDAHULUAN}

Kemampuan membaca menjadi hal yang penting di masyarakat. Sebab, melalui membaca kita dapat memperoleh berbagai informasi dan wawasan serta pengetahuan baru. Membaca merupakan sebuah aktivitas positif yang dapat memberikan manfaat yang besar. Membaca dapat menambah pengetahuan dan berkaitan erat dengan kecerdasan seseorang. Hal tersebut dikarenakan aktivitas membaca dapat merangsang bagian-bagian yang ada dalam otak manusia. Terdapat suatu hubungan yang erat kaitannya antara minat membaca, kebiasaan membaca, dan kemampuan untuk membaca. Rendahnya minat membaca dapat mengakibatkan kebiasaan membaca yang kurang, sehingga dapat menjadikan kemampuan membaca menjadi rendah pula.
Dalam kehidupan yang sangat kompleks seperti sekarang ini, masyarakat banyak dituntut untuk memiliki kemampuan membaca yang baik. Kemampuan membaca yang baik dapat diperoleh dengan banyak membaca. Membaca merupakan suatu kegiatan yang dapat menambah wawasan dan menjadi hiburan bagi beberapa orang. Kegiatan membaca yang dibiasakan sejak dini dapat memperluas pengetahuan, merangsang kreativitas, dan semangat rasa ingin tahu seseorang.

Di era globalisasi seperti zaman sekarang ini, telah banyak beredar buku digital atau biasa disebut dengan e-book yang dapat lebih memudahkan orang-orang untuk membaca. Namun, minat masyarakat tetaplah rendah untuk membaca. Penyebab rendahnya minat baca masyarakat dapat dipengaruhi oleh berbagai hal. Salah satunya yaitu dari lingkungan yang ada di 
sekitar. Dimulai dari keluarga, teman, dan sekolah. Diperlukan membudayakan membaca sejak dini di lingkungan keluarga atau rumah agar anak-anak memiliki minat membaca yang lumayan tinggi sejak kecil. Selain itu, di setiap sekolah juga seharusnya diterapkan gerakan membaca buku non-pelajaran sebelum memulai pelajaran agar anak-anak senantiasa dalam lingkungan membaca terus menerus sehingga keinginan untuk terus membaca tetap ada. Namun, di era saat ini, anak-anak maupun orang dewasa lebih disibukkan dengan gadget, game online, dan social media. Hal tersebutlah yang menyebabkan minat membaca masyarakat di Indonesia masih sangatlah rendah. Oleh karena itu, dibuatlah Taman Baca yang difungsikan tidak hanya sebagai tempat untuk membaca, namun juga sebagai tempat rekreasi maupun hiburan untuk masyarakat di Kota Banjarbaru sekaligus untuk menunjang kebutuhan membaca.

Desain Taman Baca ini menyuguhkan tempat membaca dengan konsep yang berbeda dari perpustakaan atau Taman Baca lainnya dengan memfasilitasi ruang baca dengan berbagai variasi ruang baik indoor maupun outdoor sehingga pengunjung dapat merasa nyaman saat membaca.

\section{PERMASALAHAN}

Salah satu cara untuk meningkatkan minat baca masyarakat adalah dengan menghadirkan fasilitas untuk membaca yang sifatnya menyenangkan seperti sebuah taman. Permasalahan yang diangkat dalam penulisan ini adalah bagaimana rancangan Taman Baca yang dapat meningkatkan minat baca masyarakat Kota Banjarbaru dengan konsep sebagai tempat rekreasi?

TINJAUAN PUSTAKA

\section{A. Pengertian Judul}

Menurut buku Pedoman Taman Bacaan Masyarakat (Sutarno N. S., 2006:9), Taman Bacaan Masyarakat merupakan sebuah tempat yang didirikan untuk kemudian dikelola oleh pemerintah atau masyarakat (individu atau sebuah instansi) untuk memberikan akses atau sebagai penunjang kegiatan membaca masyarakat sekitar sebagai sarana pembelajaran dalam rangka peningkatan minat baca dan kualitas hidup masyarakat.

Juga menurut buku Pedoman Taman Bacaan Masyarakat (Sutarno N. S., 2006: 19), Taman Bacaan Masyarakat mempunyai tanggung jawab, wewenang, dan hak masyarakat setempat dalam membangunnya, mengelola, dan mengembangkannya. Dalam hal ini, perlu dikembangkan rasa untuk ikut memiliki (sense of belonging) dan ikut bertanggung jawab.

Sedangkan menurut Amrin (2011: 04), Taman Bacaan Masyarakat adalah sebuah lembaga atau unit layanan berbagai kebutuhan bahan bacaan yang dibutuhkan dan berguna bagi setiap orang atau sekelompok masyarakat di desa atau di wilayah Taman Bacaan Masyarakat berada dalam rangka meningkatkan minat baca dan mewujudkan masyarakat berbudaya baca.

Dari penjelasan di atas, dapat dipahami bahwa Taman Bacaan Masyarakat adalah lembaga atau unit layanan yang menyediakan bahan bacaan untuk sekelompok masyarakat di suatu wilayah dalam rangka meningkatkan minat baca masyarakat. Masyarakat menyadari dan menghayati bahwa Taman Bacaan sangat diperlukan oleh masyarakat. Minat masyarakat terhadap membaca dan juga Taman Bacaan Masyarakat harus terus dibina dan dikembangkan sehingga 
masyarakat dapat memperoleh informasi yang mereka perlukan dari buku-buku yang disediakan oleh Taman Baca.

Menurut Buku Pedoman Pengelolaan Taman Bacaan Masyarakat (Sutarno N. S., 2006:1), tujuan Taman Bacaan Masyarakat adalah :

1. Membangkitkan dan meningkatkan minat baca masyarakat sehingga tercipta masyarakat yang cerdas dan selalu mengikuti perkembangan ilmu pengetahuan dan teknologi.

2. Menjadi sebuah wadah kegiatan belajar masyarakat.

3. Mendukung peningkatan kemampuan aksarawan baru dalam pemberantasan buta aksara sehingga tidak menjadi buta aksara kembali.

Dari tujuan tersebut, Taman Baca menjadi sumber pembelajaran untuk masyarakat sekitar.

\section{B. Kebutuhan Ruang}

Ruang-ruang maupun fasilitas pada Taman Baca dapat ditentukan dengan cara menganalisis pelaku atau pengguna Taman Baca dan aktivitas yang dilakukan di dalamnya. Ruang-ruang yang ada pada Taman Baca dikategorikan menjadi 4 bagian, yaitu :

1. Ruang administrasi

a. Lobby, sebagai tempat untuk menerima dan melayani pengunjung

b. Ruang karyawan termasuk kepala pengelola

c. Ruang rapat

d. Ruang arsip, untuk pendataan buku-buku yang ada di Taman Baca

2. Ruang untuk kegiatan perpustakaan a. Ruang Baca untuk anak dan dewasa (indoor dan outdoor)

b. Ruang Buku untuk anak dan dewasa (indoor dan outdoor)

3. Ruang service
a. Toilet
b. Pantry untuk karyawan
c. Tempat parkir

4. Fasilitas Penunjang
a. Ruang belajar
b. Ruang bermain untuk anak (indoor dan outdoor)
c. Cafe
d. Toko Buku

Aktivitas yang terjadi di Taman Baca akan menentukan tata ruang atau layout Taman Baca. Perletakan ruang dapat dipengaruhi oleh hubungan dan sifat tiaptiap ruang yang ada, sirkulasi, dan zonasi yang digunakan.

\section{PEMBAHASAN}

\section{A. Lokasi}

Lokasi Tapak memiliki luas $\pm 10.000 \mathrm{~m} 2$ yang berdekatan dengan berbagai bangunan pendidikan seperti Kampus Uniska Banjarbaru, SDN 1 Guntung Paikat SMPN 1 Banjarbaru, bangunan ibadah berupa masjid, gereja, musholla, fasilitas umum seperti RTH (Ruang Terbuka Hijau), Taman, Kolam Renang, Kampung Pelangi, dan berbagai bangunan sarana-prasarana lainnya.

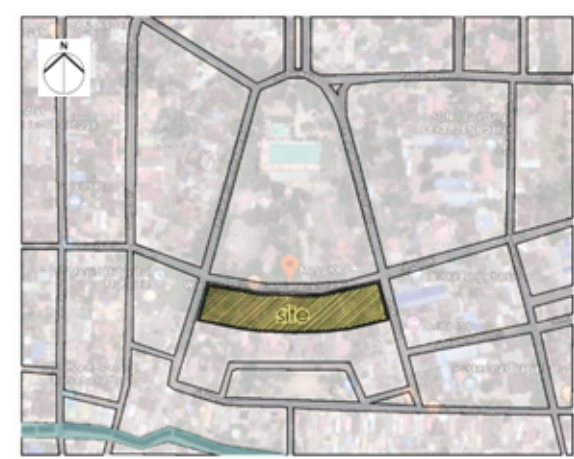


Gambar 1. Lokasi Tapak

Sumber: Dlolah dari google maps koordinat $3^{\circ} 26^{\prime} 46.0^{\prime \prime S} 114^{\circ} 49^{\prime} 57.1^{\prime \prime} E$

\section{B. Konsep Programatik}

Konsep programatik merupakan konsep yang digunakan untuk menyelesaikan permasalahan yang ada dan mencapai tujuan yang diinginkan. Permasalahan yang ada yaitu minat baca masyarakat di Indonesia yang tergolong rendah dan tidak terfasilitasinya masyarakat untuk membaca. Oleh karena itu, diadakan Gerakan Minat Baca (GMB) oleh pemerintah untuk meningkatkan minat baca masyarakat. Salah satunya dengan membangun Taman Baca di banyak daerah yang tersebar di seluruh Indonesia. Namun, itu saja dinilai kurang dalam hal meningkatkan minat baca, karena setelah difasilitasi tempat untuk membaca, minat masyarakat Indonesia terhadap membaca masih sangatlah rendah. Lalu, dicarilah sesuatu yang unik dan tidak membosankan dan kekinian seperti zaman sekarang, yaitu menggabungkan tempat untuk membaca dan rekreasi. Dan didapatlah konsep "Recreational Space" untuk mendukung Gerakan Minat Baca tersebut dengan membuat sebuah Taman Baca yang sekaligus dapat menjadi tempat rekreasi untuk menarik minat masyarakat sekaligus dapat meningkatkan minat baca. Konsep "Recreational Space" itu sendiri nantinya akan diterapkan ke dalam berbagai aspek Taman Baca seperti interior, eksterior, bentuk bangunan, tata massa bangunan, maupun aktivitas di dalamnya.

\section{Konsep Desain}

\section{Konsep Zonasi}

Rancangan Taman Baca dibagi menjadi ke dalam tiga zonasi, yaitu zona service yang terdapat parkiran untuk pengunjung dan staff, zona taman atau spot-spot outdoor untuk membaca buku, dan zona bangunan yang digunakan untuk keperluan administrasi dan ruang-ruang seperti toko buku, ruang buku, dan ruang untuk membaca.

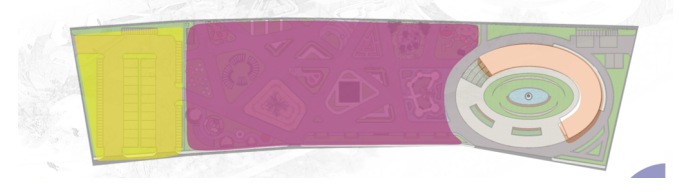

Gambar 2. Konsep Zonasi Taman Baca

\section{Konsep Bentuk Bangunan}

Bentuk bangunan memiliki ide awal berbentuk lingkaran, lalu diberi volume dan ditarik sisi kanan dan kirinya sehingga menjadi berbentuk ellipse. setelah itu, bagian tengahnya dibuat berlubang agar memberi kesan yang tidak masif dan dipotong di sebagian sisinya yang akhirnya memiliki bentuk akhir terbuka di sisinya.
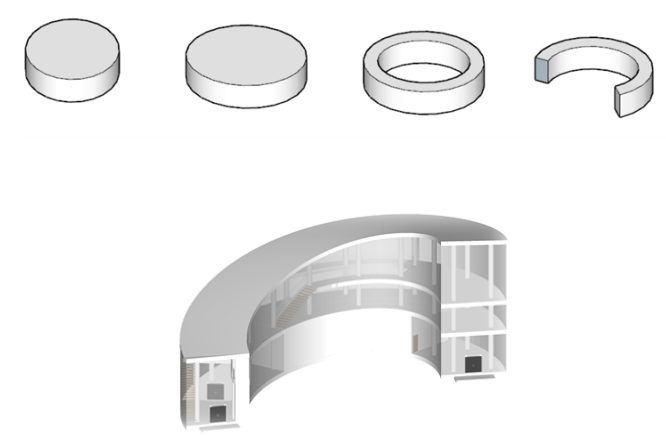

Gambar 3. Konsep Bentuk Bangunan Taman Baca

\section{Konsep Sirkulasi}

Sirkulasi yang ada di Taman Baca ini menggunakan sistem sirkulasi yang bercabang (branching) yang berfungsi sebagai penghubung antar zona di Taman Baca dan antar spot di taman sekaligus sebagai jalan masuk menuju ke bangunan Taman Baca. 


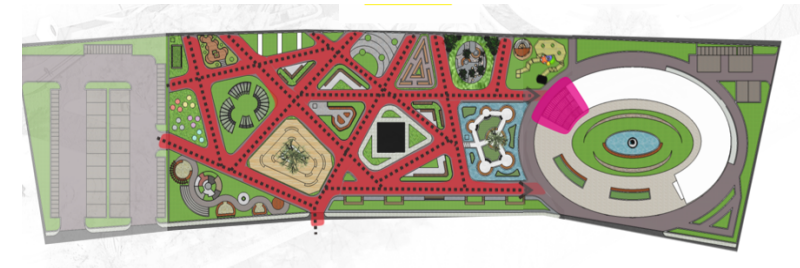

Gambar 4. Konsep Sirkulasi pada Taman Baca

\section{Konsep Taman}

Zona taman yang ada di Taman Baca ini dibuat berdasarkan analisa pose saat membaca buku, yaitu membaca dengan duduk, membaca di meja, membaca dengan santai, membaca sambil bersandar, membaca sambil tengkurap, dan membaca sambil rebahan. Dari analisis yang telah dilakukan, maka dibuatlah berbagai spot untuk membaca buku.

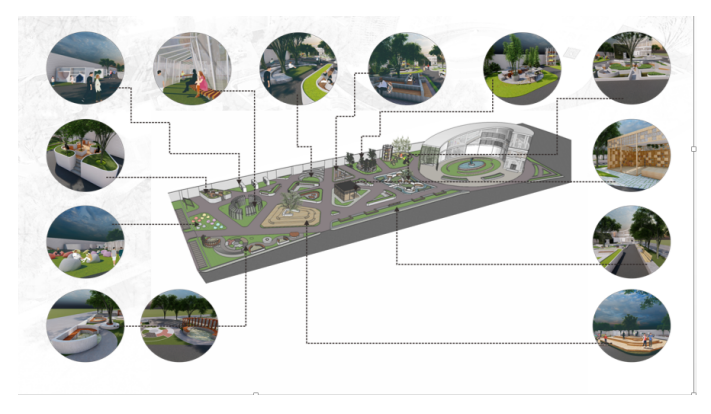

Gambar 5. Konsep Taman pada Taman Baca

HASIL

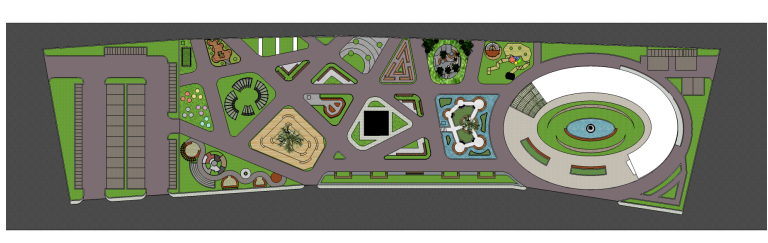

Gambar 6. Siteplan Taman Baca

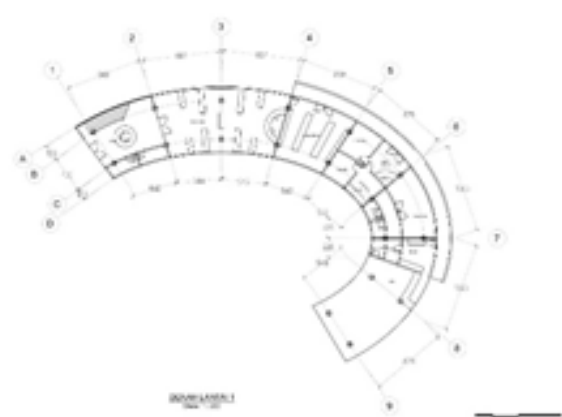

Gambar 7. Denah Lantai 1 Bangunan Taman Baca

Gambar 8. Denah Lantai 2 Bangunan Taman Baca

Gambar 9. Denah Lantai 3 Bangunan Taman Baca

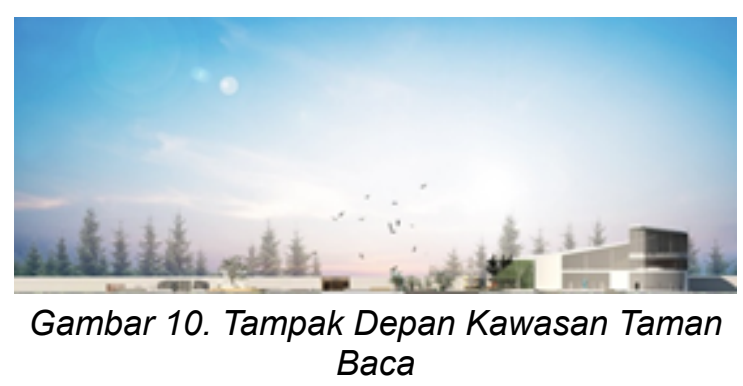




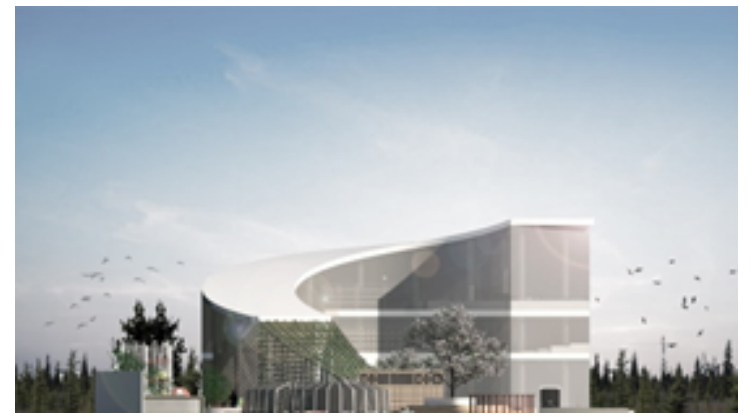

Gambar 11. Tampak Kiri Kawasan Taman Baca

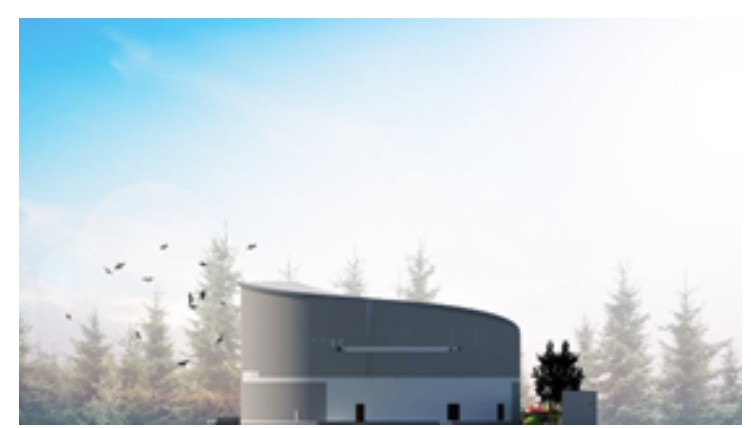

Gambar 12. Tampak Kanan Kawasan Taman Baca

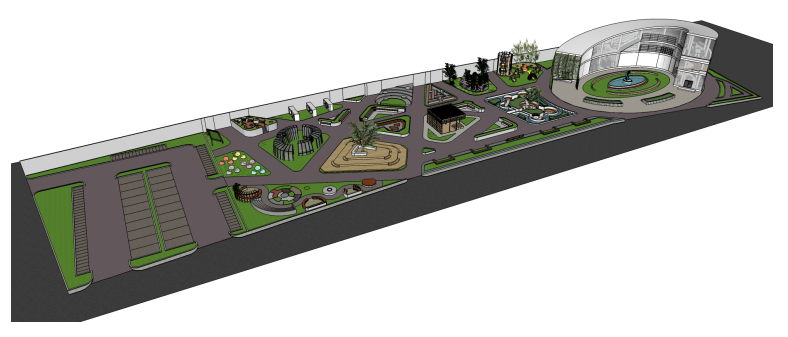

Gambar 13. Perspektif Kawasan Taman Baca

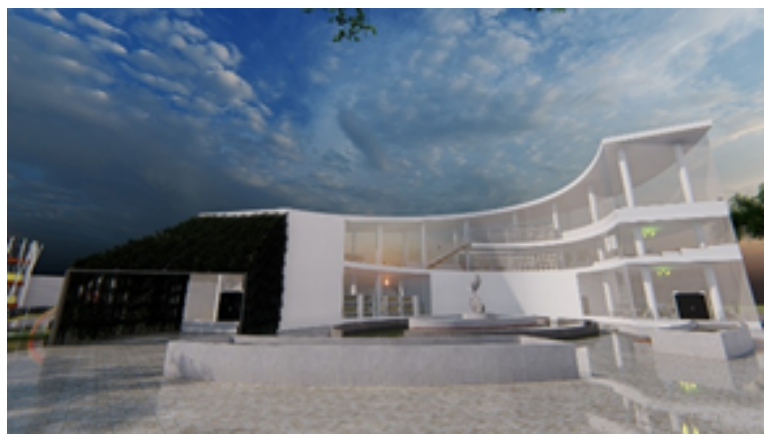

Gambar 14. Perspektif Bangunan Taman Baca
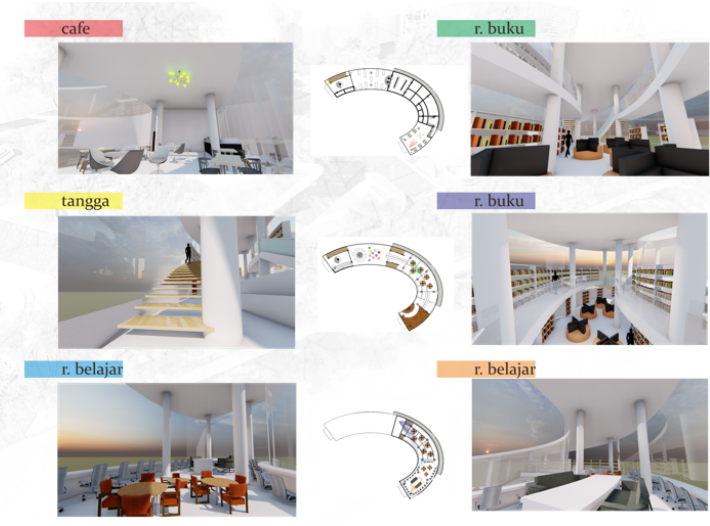

Gambar 15. Perspektif Interior Bangunan Taman Baca
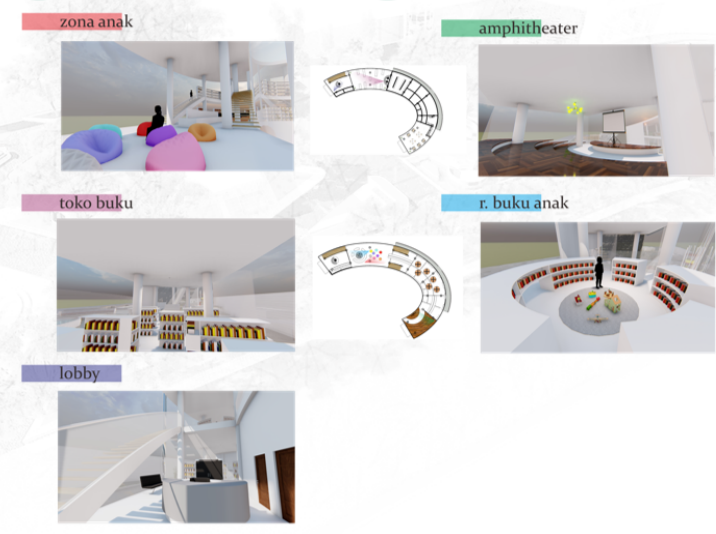

Gambar 16. Perspektif Interior Bangunan Taman Baca 


\section{KESIMPULAN}

Perancangan Taman Baca ini merupakan solusi untuk meningkatkan minat baca masyarakat yang rendah sekaligus menyediakan fasilitas untuk membaca dan memperoleh berbagai informasi. Metode yang digunakan dalam rancangan ini adalah metode Programming dengan cara problem solving.

Sedangkan konsep yang digunakan pada rancangan Taman Baca ini adalah Recreational Space, yaitu mengubah konsep perpustakaan yang dinilai membosankan menjadi sebuah Taman Baca yang rekreatif, nyaman, variatif, dan memiliki fasilitas cukup lengkap. Jadi Taman Baca ini bukan hanya menjadi tempat untuk membaca saja, namun pengunjung atau masyarakat juga dapat berekreasi di dalamnya.

Penerapan dari konsep Recreational Space di Taman Baca ini ada pada bentuk bangunan yang cukup unik sehingga dapat menarik minat masyarakat dan penasaran akan bangunan Taman Baca, fasilitas yang disediakan cukup memadai dan lengkap, serta penambahan beberapa fungsi lain pada Taman Baca seperti toko buku, cafe, ruang bermain anak, ruang belajar, dan taman. Jadi, dengan diterapkannya hal-hal tersebut, maka diharapkan masyarakat akan tertarik untuk memasuki kawasan Taman Baca dan melakukan aktivitas di dalamnya.

Selain itu, diharapkan pula akan semakin banyak orang yang membaca dan menyukai buku, serta beranggapan bahwa membaca tidak lagi hanya dipandang sebagai sesuatu yang membosankan, tetapi juga menyenangkan.

\section{DAFTAR PUSTAKA}

\section{Referensi Buku dan Jurnal}

Sinaga, Dian. 2005. Perpustakaan Masyarakat. Jakarta: Kreasi Media Utama.

Sutarno NS. 2006. Manajemen Perpustakaan. Jakarta: Sagung Seto.

Sutarno NS. 2006. Membangun Taman Bacaan Masyarakat. Jakarta: Gramedia.

Sutarno NS. 2008. Membina Perpustakaan Desa. Jakarta: Sagung Seto.

Muhammad, Hamid. 2010. Taman Bacaan Masyarakat. Jakarta : Djambatan Panduan.

Amrin. 2011. Acuan Pengelolaan Taman Bacaan Masyarakat . Medan: Pustaka TBM MRD.

Angkasa Tarigan, H. 2013. Membaca sebagai suatu keterampilan berbahasa. Bandung: Angkasa.

Mentari, Bunga Nisa. 2015. Meningkatkan Minat Baca Masyarakat Melalui Program Perpuseru Dalam Pengelolaan Taman Bacaan Masyarakat Berbasis Information Technology, Bandung. 